\title{
Job attitude and education attainment for professional identity
}

\author{
Sakuntala Pageni \\ pagenisakuntala@gmail.com
}

\begin{abstract}
This paper's job attitude and educational attainment try to identify the present condition in the context of job attitude and educational attainment. The purpose of this study is based on the relationship between qualification and job performance. Generally, job attitude is built on through career development, professional identity, job satisfaction job performance, and the job description which are concerned with the total attitudes towards the various aspects of the working condition of individual perception for holistic index. However, attitudes do not cause variation in attainment but opportunity cost, salary, and policies, and practices of company and government continue to be effective. This paper includes a theoretical concept behind job satisfaction which is the human relation theory of George Elton Mayo and the theory of equity of Stacy Adams. This paper is a review-based paper based on different related research article theories and books. To fulfill the aims of the study using a qualitative descriptive method to establish a relationship between the job attitude and education attainment. The main issue of this paper focuses on the working class and people's attitude towards the attainment of jobs and its utilization.
\end{abstract}

Keywords: Education attainment, Job attitude, professional identity

\section{Introduction}

Background: Job attitude is a set of evaluations about one's job that creates a feeling towards his work and working condition. Generally, the word attitude is defined as a personal or psychological tendency that is articulated of evaluation as a particular entity with some degree of like or dislike, whereas job attitude is particularly rigorous as an object (Hess, 2005). In other sense, the word "job" involves one's current situation or condition, one's work, or one's occupation. However, one's attitude towards his/her work does not necessarily have to be equal to one's attitude towards his or her employer. It can be positive or negative in the context of his feeling, behavior, emotion, thought, and realization. When the employees feel better his work efficiency increase and job satisfaction can achieve.

Educational attainment is defined as the highest level completed within the most advanced level attained in the whole education system of any country whereas the education system was received in a definite time frame. In other words, it refers to the level of schooling a person completed. Educational attainment, job attitude, and job satisfaction are interrelated with each other (Clark, 1986). So, we can say that job satisfaction can create a positive job attitude.

Educational attainment refers to the degree or level of completed education of a person based on the elementary, high school, technical, vocational, Bachelor's degree, master's degree, graduate school, and Doctorate in Post Graduate studies. It creates a job-related attitude increase in terms of job satisfaction (McQueen, 2007).

The obtaining of educational attainment implies the successful completion of a specific course of study or training program while job insolence refers to an individual output in terms of quality and quantity aspect from the particular job. In some cases, workers are not well-matched with their current jobs. Who is capable of better handling more complex tasks and their skills are useful? While others are under-skilled for their current jobs as the lack of qualification is normally needed to deliver in their jobs (Pine, 2000).

The educational qualifications have a significant bearing on job performance. If the educational level is high more are the effects of education and skill on job performance. The educated workers to being more responsive in receiving new tasks and easily adopt new technology. On the other hand, educational attainment on job performance at the workplace includes the improvement of the work environment (Kasika \& Wendo, 2015). Many people participate to work with various levels of job expectation which is not only related in quality but also in intensity (different people may value different things in a job) based on working experiences, people receive a reward from the job. It is not only extrinsic such as payment and promotion but also intrinsic reward. Such as, the level of satisfying relationship asked between co-workers, work environment, and meaningful work. However, outcomes do not meet exceptions employees are dissatisfied and may prefer to seek alternative sources and ways of satisfaction. Generally, there are several dimensions of job satisfaction which is work itself, payment, promotion, opportunities, supervision, co-workers (Porter \& Steers, 1973). Education attainment and job satisfaction are concerned with the total attitudes towards the various aspects of the working condition of individual perception in a holistic way. However, attitudes do not cause variation in attainment but opportunity cost, salary, policies, and practices of company and government continue to be effective.

Career development is the sequence of position job occupation, occupied during a person's working 
life. Career choice plays a vital role in intrinsically or extrinsically. Carrier's role is related to environment opportunity and personality which plays varying roles in career outcomes (Aminu \& Timothy, 2014).

Therefore, study intends to examine the effect of academic qualifications on overall organizational performance of job attitude. There are a lot of different partly interacting reasons for the low levels of productivity like the low number of qualified. The purpose of the study is to identify the role of educational attainment for job attitude and to explore the relationship between educational attainment and job requirements, mainly educational qualifications and competencies of employees. In this research educational attainment should be limited to the accredited degree, diploma's, certificates within different professionals' titles that an individual has acquired whether by full-time study, part-time study, or private study, whether conferred in the home country or abroad.

Get into the habit of being punctual, arrive to work on time, and work a positive attitude every morning. Being 10 to 15 minutes early allows you to take breaks as scheduled and return promptly. Never leave work before the shift is over unless otherwise told to do so. Manage your work time. Think of your daily duties and organize your days in such a way that your duties and organize days in such a way that your duties are fulfilled attentively and in good time (Morrison, 2005). Job attitudes affect interpersonal work relationships. A positive attitude can engender a sense of cooperation among workers. Job attitudes are related to negative or positive attitudes.

For evaluation of self-esteem and strengthening the belief and value of those who did the attracting communications and the negative attitude can be harder to communicate with because they tend to shut down or close themselves off from interacting with others (Gurbug, 2011). Job attitude and satisfaction is concerned with the total attitudes towards the various aspects of work conditions. It is an important task of managerial work. It's based on the reliance deviation and improves quality in the output gained in the end. It is related to the knowledge to achieve individual and organizational aims. Despite this family reason education level, culture, job experience, social organism, and the environment take an active part in job satisfaction.

According to (Liuxxu, 2011) a review of literature about language teachers shows that the three main themes are related. The first is the relationship between the teacher's linguistic positions and professional identity; the second theme explores conflicts between social and professional identity. Then the third theme explores how teacher identity is a mediated role of power relations in the process of identity formation exerts a strong influence.

According to Lasky (2005) teacher professional identities are how the teacher understands and defines their professional roles. This dynamic construct has been have significant effect on teacher development and student performance from a socio-cultural perspectives even learning to teach is a basic process of professional identity construction rather than the acquisition of knowledge, therefore the significant to which teacher education process lead to positive changes can be largely determined by the identities that teacher bring to context and how they reconstructed during teacher education.

The professional identities is what any teacher follow in everyday practices when the teacher assumes his/her practice as critical reflection of processing the teacher can be allow their different practices and consequently modify their different beliefs conceptions and personal theories based practices that are used as teachers assumption in their practices identifies are related with different dimensions of identities (R Hermans, 2008). Teacher identity as negotiated experiences where teachers define who they are and what experiences should themselves.

There are many important consideration and respect for other employees. Good communication can create in a positive manner. Listen newly and give praises when it is deserved. Think about followers, all employees are equals even if they have a lower job rank. Avoid gossiping and talking behind the back of others.

Economic gain is not the only reason to make a commitment to higher education attainment. Many studies show that college graduates also realize many intangible benefits (Gunlu, 2010). There is much theory related to job attitudes and educational attainment which supports job effectiveness.

In the 1920s, George Elton Mayo, the pioneering scholar of human relation theory an Australian-born psychologist and organizational theorist, began his research on the behavior of people in groups and how it affects individuals in the workplace, known as the Hawthorne studies (Mayo, 1949). After the time of 1950 decades F. W Taylor, Henry Foyal are focused on increasing work efficiency or the application of science in the workplace to improve productivity, viewing individuals as machines that could work in unethical or unrealistic environments. Mayo, in contrast, popularized the idea of the "social person," meaning organizations should treat people as individuals - not machines - with individual needs (Wren, 2020). This study is concerned about job satisfaction and the professional development of employees.

The human relations theory of management is a researched belief that people desire to be part of a supportive team that facilitates development and growth. Therefore, if employees receive special attention and are encouraged to participate, they perceive their work as having significance and are motivated to be more productive, resulting in high-quality work. There are many different parts of coordination. Which are directly related to creating better and favorable conditions for employers.

In 1963, John Stacey Adams introduced the idea that fairness and equity are key components of a 
motivated individual for the job attitude (Deconinck, 2007). Equity theory is based on the idea that individuals are motivated by fairness, and if they identify inequities in the working place input or output ratios of themselves and their referent group, they will seek to adjust their input to reach their perceived equity. Adams suggested that the higher an individual's perception of equity, the more motivated they will be and vice versa: if someone perceives an unfair environment, they will be de-motivated for the working life.

The easiest way to see the equity theory at work, and probably the most common way it does impact employees, is when colleagues compare the work, they do to someone else that gets paid more than them. Equity theory always concerns about working conditions and favorable conditions. At any time, employees say things like, 'John gets paid a lot more than me, but doesn't do nearly as much work,' or 'I get paid a lot less than Jane, but this place couldn't operate without me!' In each of those situations, someone is comparing their effortto-compensation ratio to someone else's and is losing motivation in the process.

The emphasis of the approach on well-being and the expansion of individual freedoms relates to an understanding of education as intrinsically valuable. Being educated provides and enhances the possibility of engaging in activities that contribute to one's fulfillment in life and are not simply instrumental in securing better jobs or positions in society.

The capabilities approach highlights how, for instance, being introduced through education to the appreciation of literature, or science, or different kinds of music, leads to forms of personal fulfillment and personal reflection that have their inherent value. On the other hand, the approach importantly points to the several instrumental aims served by education, which are fundamental in attaining better life prospects and career opportunities, as well as in promoting forms of social and economic development. Education, and specifically formal schooling (however imprecise and questionable this distinction may be), is crucial in securing standards of living since it allows the acquisition of knowledge and skills that play an important role both for well-being and for the exercise of agency (J Ballet, 2011).

\section{Methodology}

This study job attitude and educational attainment is the concept with more interrelated association with human behaviors and job satisfaction of employees. whose holistic analysis focuses on the qualitative and descriptive design of the study with the relationship among interrelated variables. The behaviors of human activities are complex to measure within all the conditions but a qualitative perspective only suitable for the study. On the side, this document analysis also tries to find out the association of job attitude and educational attainment using studying library, internet searching, and online search and content presentation for thematic analysis. This theoretical study generalized the ontological and epistemological aspects of the methodological process of research methodology used in the field of modern educational research.

This study is based on three different theories which are human relation theory, equity theory, and the capabilities approach. For the completion of this paper, researchers firstly search books, internationally published articles, research reports, concerning theory and other documents. This study focuses on the qualitative aspects of job attitude and education attainment in the field of educational research.

However, this study summarizes the human relation theory focuses on the effectiveness of any organization depends on the quality relationship of the organization. According to Elton Mayo, a factory is not only a techno-economic unit but a psycho-social organization also. The norms and values of such small groups have a significant influence on the behavior and performance of the workers. Therefore, physical conditions of work have a greater influence on the workers' productivity where the workers act or re-act not as individuals but as the members of a group. The workers are not economic men motivated by money alone. They respond to the total work situation including recognition, participation, etc. Informal leaders play an important role in setting and enforcing group norms. The managers must understand and recognize the inter-personal and group relations on the job.

The theory is built on the belief that employees can be demotivated by employers and job conditions. If they feel as though their inputs are greater than their output. The employees can be expected to respond to output exists. The inputs typically include effort, loyalty, hard work, skill and ability, adaptability, flexibility, acceptance of others, support to colleagues, personal sacrifice, and so on. Similarly, the output typically includes financial reward recognition, reputation, responsibility, sense of achievement, praise, stimulus, job security, and so on

In the context of the above theory which is directly related to the job attitude and education attainment. In both areas always focus on the satisfaction of employees. The human relation theory demanded that a good relationship between the working class and the middle class. If the manager or top-level employers to concern about the feeling, happiness, need, and motivation of employees. He feels better and can-do work perfectly. The next theory of equity also emphasizes the equitable working environment in the organization. If the employees feel that any type of discrimination he doesn't motivate about his work. In other words, the equity theory is concerned about the well-being of employees and the expansion of personal freedom for better working achievement. The next theory also emphasizes the capacity of workers which are made by education attainment. In these theories are different areas to gain for working efficiency and the better condition of the working environment for working place.

The most important contribution made by job attitude and educational attainment in the field of human 
resource planning and management. In the context of job attitude which is influenced by job satisfaction of employees when the job situation is favorable his/, her performance increasable but the job condition or job context is not supportive he /she cannot do work smoothly. This study explores an association between educational attainment and job satisfaction. There is not more research related to educational attainment but there were very little researches on job attitude.

There are many aspects related to job attitudes and educational attainment. In other sense job, attitudes represent the position of employers, working conditions, and working environment which are needed for better achievement and job satisfaction. There is a need for quality education and human resource planning and development on how best to do a job whether public or private educational institutions depend on capital, physical, and human resources. More generally among these resources, human resources are seen as the pivot because it manipulates other resources for a desirable end product.

The main aspects considered to limit the positive effect of educational attainment on job attitude at the workplace include the quality of the working condition, organizational structures, and process assigned to the employees in the post which did not match their qualifications and the lack of incentives system.

\section{Conclusion and Reflection}

This paper entitled the job attitude and educational attainment of working its assimilation for delectating the knowledge. Job attitude depends on various types of working conditions. If the working condition is favorable for us it makes more job satisfaction which is a positive expressive response that can be experienced in our workplace and working situation.

It is an unquantifiable system of measurement however the measurements were being in some qualitative terms with social values attainment. In the place under the same condition, the factors that help one employee feel better or other employees do not feel good. Generally, it is becoming a socio-cultural, economic, moral value, and norms with social values. Generally positive thinking and a good attitude help better your psychological well-being and help you to cope better under stressful situations at work. A positive attitude shows the employees, managers, and leaders that the employers are ready to tackle anything. Having a good attitude at the workplace and condition can help to solve problems more effectively. There are growing challenges at work that arise every day. The importance of attitude in the workplace is that it affects everyone around you, whether positively and negatively. However, outcomes do not meet exceptions employees are dissatisfied and may prefer to seek alternative sources and ways of satisfaction. Generally, there are several dimensions of job satisfaction which are work itself, payment, promotion, opportunities, supervision, coworkers' vision, carrier development, and satisfaction (Porter \& Steers, 1973).

It is a multidimensional approach to employee satisfaction based on three models which are related to work conditions, upgrades the position, respected behavior, comprehensive policies, security, and so on. The theory of equity and human relation theory also believes that human resources planning management and satisfaction increase the productivity of an organization. Thus, persistence towards educational attainment is more valuable beyond, individual or business advantages. In other words, education is a key component in addressing economic and global issues. Generally, job attitude is built on through career development, professional identity, job satisfaction job performance, and the job description which are concerned with the total attitudes towards the various aspects of the working condition of individual perception for holistic index.

The focus of the related theories always wants a favorable working environment for workers. If the employees are satisfied, they can work properly and gain the maximum output and huge production for organizations. Then the organization becomes a successful or well-being organization among other organizations.

The job attitude always focuses on the work efficiency of employees. If the employees are satisfied and motivated by the working conditions. They always think about Their daily duties and organize our days in such a way that our duties and organize days in such a way that your duties are fulfilled attentively and in good time (Morrison, 2005). Job attitudes affect interpersonal work relationships. A positive attitude can engender a sense of cooperation among workers. Job attitudes are related to negative or positive attitudes. The negative attitude decrease in worker works efficiency and the positive attitude moving on the organization increase.

\section{References}

1. Aminu, M., \& Timothy, J. (2014). Career choice and academic performance of microbiology students in Nigerian university.

2. Clark, B. (1986). The higher education system: Academic organization in cross-national perspective.

3. DA Wren, A. B. (2020). The evolution of management thought.

4. E Gunlu, M. A. (2010). Job satisfaction and organizational commitment of hotel managers in Turkey.

5. E Mayo, M. F. (1949). Organization theory.

6. Gurbug, A. (2011). An assessment on the effect of education level on the job satisfaction from the tourism sector point of view.

7. J Ballet, M. B. (2011). Children's agency and the capability approach: A conceptual framework. 73. 
8. J Deconinck, D. B. (2007). THE IMPACT OF EQUITY SENSITIVITY AND PAY FAIRNESS ON MARKETING MANAGERS JOB SATISFACTION, ORGANIZATIONAL COMMITMENT.

9. JA LePine, J. C. (2000). Adaptability to changing task contexts: Effects of general cognitive ability, conscientiousness, and openness to experience.

10. Kasika, B., \& Wendo, D. (2015). The effect of educational qualification on job performance: The case of social security commission in Namibia. Namibia

11. McQueen, M. (2007). Motivators of job satisfaction for elementary school principals in central Virginia

12. Morrison, R. L. (2005). Informal relationships in the workplace: Associations with job satisfaction, organizational commitment and turnover intentions.

13. Porter, L. W., \& Steers, R. M. (1973). Organizational work and personal factors in employee turnover and absenteeism. Psychology Bulletin.

14. R Hermans, J. T. (2008). The impact of primary school teachers' educational beliefs on the classroom use of computers.

15. RD Hess, J. T.-P. (2005). The development of political attitudes in children. 